\title{
Segurança Alimentar, produção de alimentos e saúde: um olhar para os territórios agrícolas de Mato Grosso
}

\author{
Marcia Leopoldina Montanari Corrêa ${ }^{1}$ \\ Wanderlei Antônio Pignati ${ }^{2}$ \\ Marta Gislene Pignatti3 \\ Universidade Federal de Mato Grosso
}

Resumo: O modelo de produção de alimentos pautado no uso de insumos químicos, produção de monocultivos e transgenia traz consequências à saúde $\mathrm{e}$ segurança alimentar das pessoas e dos territórios, impondo-se como hegemônico. O presente ensaio parte das reflexões teóricas de uma pesquisa sobre contaminação de alimentos realizada na região da Bacia do Rio Juruena em Mato Grosso entre os anos de 2015 e 2018 e discute a imposição aos agrotóxicos como categoria presente na determinação social do processo saúde doença naquele território.

Palavras-chave: Segurança Alimentar, Resíduos de Agrotóxicos; Produção de Alimentos; Saúde Ambiental.

\footnotetext{
${ }^{1}$ Nutricionista, mestre em Saúde Coletiva, doutoranda do Programa de Pós-Graduação em Saúde Coletiva. Docente do Instituto de Saúde Coletiva (UFMT).

${ }^{2}$ Médico, mestre em Saúde e Ambiente (UFMT) e doutor em Saúde Pública pela Escola Nacional de Saúde Pública da Fundação Oswaldo Cruz. Professor titular aposentado do Instituto de Saúde Coletiva da UFMT.

3 Graduada em Ecologia pela (Unesp), mestre e doutora em Saúde Coletiva (Unicamp). Professora titular do Instituto de Saúde Coletiva da UFMT.
} 


\title{
Food Security, food production and health: a look at the agricultural territories of Mato Grosso
}

\begin{abstract}
The food production model based on the use of chemical inputs, monoculture production and transgenic has consequences for the health and food security of people and territories, imposing itself as hegemonic. This paper starts from the theories of a research on food contamination carried out in the Bacia do Rio Juruena region in Mato Grosso between 2015 and 2018 and discusses the imposition of pesticides as a category present in the social determination of the health disease process in that territory.
\end{abstract}

Keywords: Food Safety, Pesticides Residues; Food Production; Environmental health.

\section{Seguridad alimentaria, producción alimentaria y salud: una mirada a los territorios agrícolas de Mato Grosso}

\begin{abstract}
Resumen: El modelo de producción de alimentos basado en el uso de insumos químicos, producción de monocultivos y transgénicos tiene consecuencias para la salud y la seguridad alimentaria de las personas y los territorios, imponiéndose como hegemónicos. Este ensayo parte de las reflexiones teóricas de una investigación sobre contaminación de alimentos realizada en la región de Bacia del río Juruena en Mato Grosso entre 2015 y 2018 y analiza la imposición de pesticidas como categoría presente en la determinación social del proceso de enfermedad de la salud en ese territorio.
\end{abstract}

Palabras clave: Seguridad alimentaria; Residuos de plaguicidas; Producción de alimentos; Salud ambiental 


\section{Introdução}

agricultura é uma das mais antigas e tradicionais formas de trabalho hu-
mano, por meio da qual se superou o nomadismo e estabeleceram-se dife-
rentes formas de organização social (SANTOS, 2001). Para além da produ-
ção de alimentos e produtos para atender necessidades humanas, desde o período
pós-guerra, a terra e as formas de produção agrícola sofreram transformações
mediadas pelo avanço do capitalismo no campo e caracterizadas pela produção
das "commodities agrícolas", cujo valor de uso se dá pelos interesses do capital
que regulam os processos de importação e exportação, em detrimento das neces-
sidades de consumo. São produzidas mercadorias agrícolas para produção de bi-
ocombustíveis, como o etanol à base de cana e milho, a plantação de árvores para
produção de celulose e uso em siderúrgicas, a produçãa de grãos, como a soja, o
milho e o girassol, além de algodão, exportados como produtos primários para
outros países (ARAƯJO e OLIVEIRA, 2017).

Estes cultivos encontram no Brasil e, mais particularmente, no bioma Cerrado as condições adequadas ao manejo da produção agrícola que demanda extensas áreas, plantio de poucas espécies, uso de insumos agrícolas, maquinários, fertilizantes químicos, agrotóxicos e transgenia (PORTO e SOARES, 2012; MELGAREJO, 2018; PIGNATI e MACHADO, 2011).

O termo commodity significa literalmente "mercadoria" e designa um tipo particular de produto em estado bruto ou primário de importância comercial, (SANDRONI, 1999) cujos preços são definidos em nível global por expectativas ditadas pelos mercados internacionais, pautadas na alta volatilidade devido à natureza cíclica de seu processo produtivo, passível de crises sanitárias, adversidades climáticas, instabilidade cambial, níveis de estoques, oferta e demanda (MARTINS, 2009).

Uma commodity enquanto produto primário é utilizada na cadeia agroindustrial de alimentos processados, produção de combustíveis, roupas e outros produtos finais, retornando ao consumidor com suas características iniciais modificadas, ou seja, como um novo produto, uma mercadoria. Ainda que componha a alimentação em forma de alimento processado, o modelo de produção de commodities pode comprometer a produção e abastecimento local, reduzindo a oferta de variedades de alimentos naturais e expondo as populações e ambientes aos riscos do seu processo produtivo.

A sociedade pós-moderna produz seus alimentos para atender às demandas de consumo cada dia mais desigual. Por um lado, o ultraprocessamento de alimentos alavancado pela indústria alimentícia coloca à disposição do mercado preparações de composição pouco saudável, evidenciando o papel da mídia na formação e fidelização de novos consumidores, cujos indicadores de saúde apontam um perfil de adoecimento crônico, progressivo e altamente letal (MONTEIRO, 2009; 2013). Por outro lado, coexistem a fome, deflagrada ou oculta, daqueles que não têm acesso regular e contínuo a alimentos, de forma diversificada 
e segura com indicadores de subnutrição e insegurança alimentar (SEGALL CORREAA et al, 2009; SANTOS et al, 2018). E, de forma transversal a todo este processo de transição nutricional, epidemiológica e sanitária, consumidores de alimentos e de água estão submetidos a um processo de contaminação química derivativa do processo produtivo de alimentos e commodities agrícolas.

A produção de monocultivos, para além de seu impacto decorrente da imposição aos agrotóxicos e aos transgênicos, também pode comprometer o acesso à alimentação adequada por restringir a diversidade de alimentos disponíveis, produzidos localmente. A relação entre contaminação dos alimentos, do ambiente e produção agrícola é presumível em regiões de intensa utilização de insumos químicos, como é o caso dos municípios de Sapezal, Campos de Júlio e Campo Novo do Parecis, da região da Bacia do Rio Juruena. A soberania alimentar é necessária para a garantia da segurança alimentar e nutricional e diz respeito ao direito dos povos em definirem o que, para quem e em quais condições produzir, ou seja, representa a soberania dos agricultores e agricultoras, extrativistas, pescadores e pescadoras, entre outros grupos, sobre sua cultura e sobre os bens da natureza (CONSEA, 2017). Neste sentido, a discussão da Soberania e Segurança Alimentar também se apresenta como necessária à compreensão do processo saúde-doença nestes municípios.

O presente ensaio discute o processo de contaminação dos alimentos em sua dinâmica impositiva como um determinante de saúde em região de intensa produção agrícola no estado de Mato Grosso a partir dos pressupostos teóricos da Soberania e Segurança Alimentar e Nutricional dos Territórios. Compreende o cumprimento do Direito Humano à Alimentação Adequada como condição para o Direito à Saúde, com vistas ao qual se faz necessário discutir os modelos de produção e obtenção de alimentos, partindo do paradigma da determinação social do processo saúde-doença, que busca embasamento nos preceitos do Realismo Dialético para discutir a questão da produção de alimentos e a exposição aos agrotóxicos.

\section{Cenários de Produção Agrícola e uso de agrotóxicos em Mato Grosso}

A ocupação dos territórios de produção no Brasil não é um processo recente. Iniciou-se com os ciclos econômicos no Brasil Colônia, primeiro como parte da exploração extrativista vegetal, nos ciclos de Pau-Brasil e mineral, com a extração de ouro e outros minérios, seguindo para a produção de cana-de-açúcar, café, cacau, borracha, com os territórios ocupados por latifúndios, exploração de força de trabalho indígena e negra, produção em monocultivos, exportação para o império, lógica de poder dominada pela elite da aristocracia rural e hegemonia política e econômica do patriarcado rural (PRADO JR., 2000; HOLANDA, 2016).

Atualmente segue com a produção de soja, milho e algodão, sob os auspícios do agribusiness ou agronegócio, conceito norte-americano, cuja origem data de 1957, com a publicação do livro A Concept of Agribusiness, de John Davis e Ray Goldberg, evidenciando os avanços tecnológicos no campo e repercutindo no embate político de apoio e disseminação de seus preceitos (MENDONÇA, 2015). A evolução deste modelo pauta o período pós-Segunda Guerra Mundial, com a chamada "Revolução Verde", inaugurando a tecnificação dos processos de trabalho agrícola nos países desenvolvidos e, posteriormente, nos países em desenvolvimento, baseado nas monoculturas, utilização de insumos químicos, maquinários 
e progressiva redução da população agrícola, alterando os cenários de campesinato rural para um novo processo de agricultura mecanizada (HOBSBAWN, 2014).

Nos últimos anos, este processo tem se intensificado com a globalização que, dentre outros aspectos, trouxe ao cenário agrícola as grandes empresas transnacionais (MEDINA, 2016) e a desterritorialização da agricultura (SANTOS, 2001; BREILH, 2006), ditando as regras da produção, por meio da dominação do mercado consumidor, do próprio modelo produtivo sobre os quais ele influi e dos territórios de produção (OLIVEIRA, 2016). Segundo Milton Santos, "com a globalização, o que temos é um território nacional da economia internacional, isto é, o território continua existindo (...), ainda que as forças mais ativas do seu dinamismo atual tenham origem externa" (SANTOS, 2001: 37). Ampliam-se, dessa forma, as contradições entre os interesses internos e externos, prevalecendo os interesses externos na pauta de prioridades de governo, sem que haja uma participação nacional efetiva na governança das cadeias do agronegócio (MEDINA, 2016).

Neste contexto, o estado de Mato Grosso tem se consolidado nas últimas décadas como uma região estratégica para a expansão do agronegócio, com a utilização de extensas áreas para produção de monoculturas. Em 2017, Mato Grosso produziu $27 \%$ da soja no Brasil, em 9,2 milhões de hectares, 30\% do milho, em 4,7 milhões de hectares, e $67 \%$ do algodão em 600 mil hectares (IBGE-SIDRA/PAM, 2017).

De acordo com censo agropecuário de 2017 (IBGE, 2017), Mato Grosso apresenta quatro grandes regiões produtivas de lavouras: na porção oeste do estado, os municípios de Campos de Júlio, Sapezal, Campo Novo do Parecis, Tangará da Serra e Diamantino; no centro norte, os municípios sinalizados são Lucas do Rio Verde, Sorriso Sinop e Nova Mutum; no sudoeste estão os municípios de Primavera do Leste e Campo Verde; e, ao sul, os municípios de Rondonópolis e Itiquira. Recentemente o avanço das fronteiras agrícolas segue para o leste e nordeste do estado, abarcando municípios de Água Boa, Canarana e Querência, ampliando as áreas destinadas às monoculturas e, consequentemente, o desmatamento e a exposição aos agrotóxicos, conforme é possível observar na Figura 1.

Os maiores volumes de utilização de agrotóxicos se concentram em áreas destinadas à produção de commodities agrícolas no estado. Conforme metodologia proposta por Pignati et al (2017), que estima o volume de uso de agrotóxicos partir da área plantada, com base no consumo médio de litros de produto formulado utilizado para cada cultura agrícola, estas mesmas regiões utilizaram grandes volumes de agrotóxicos em suas lavouras no período analisado, com destaque para os municípios de Campos de Júlio, Sapezal e Campo Novo do Parecis que apresentaram uma média registrada de utilização de agrotóxicos acima de 1 milhão de litros no ano de 2017, conforme é possível observar na Figura 2. 


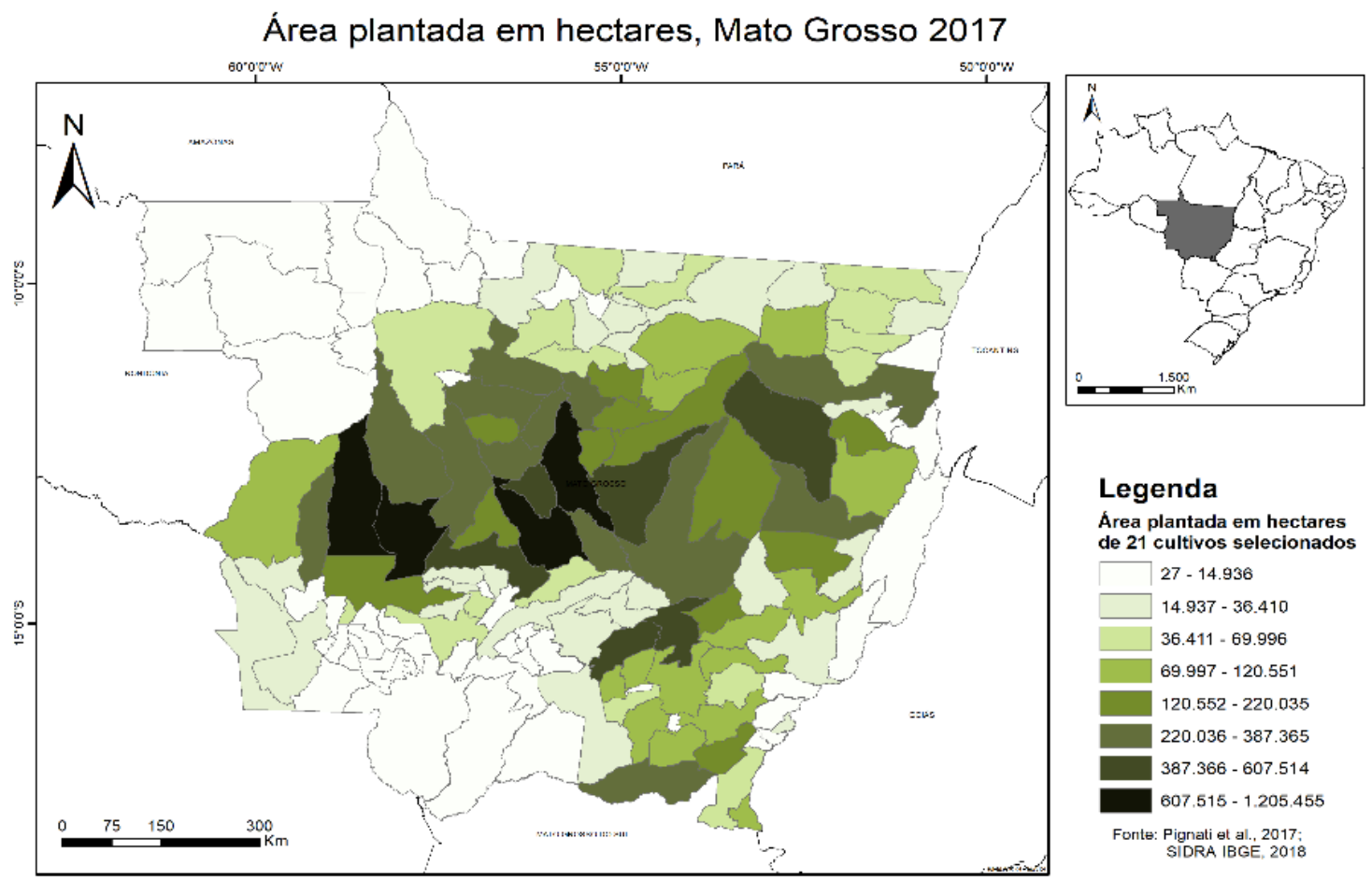

Figura 1. Mapa de área plantada nos municípios de Mato Grosso, 2017. Fonte: NEAST/ISC/UFMT, setembro de 2018.

Estimativa de consumo de agrotóxicos em litros de produtos formulados, Mato Grosso 2017
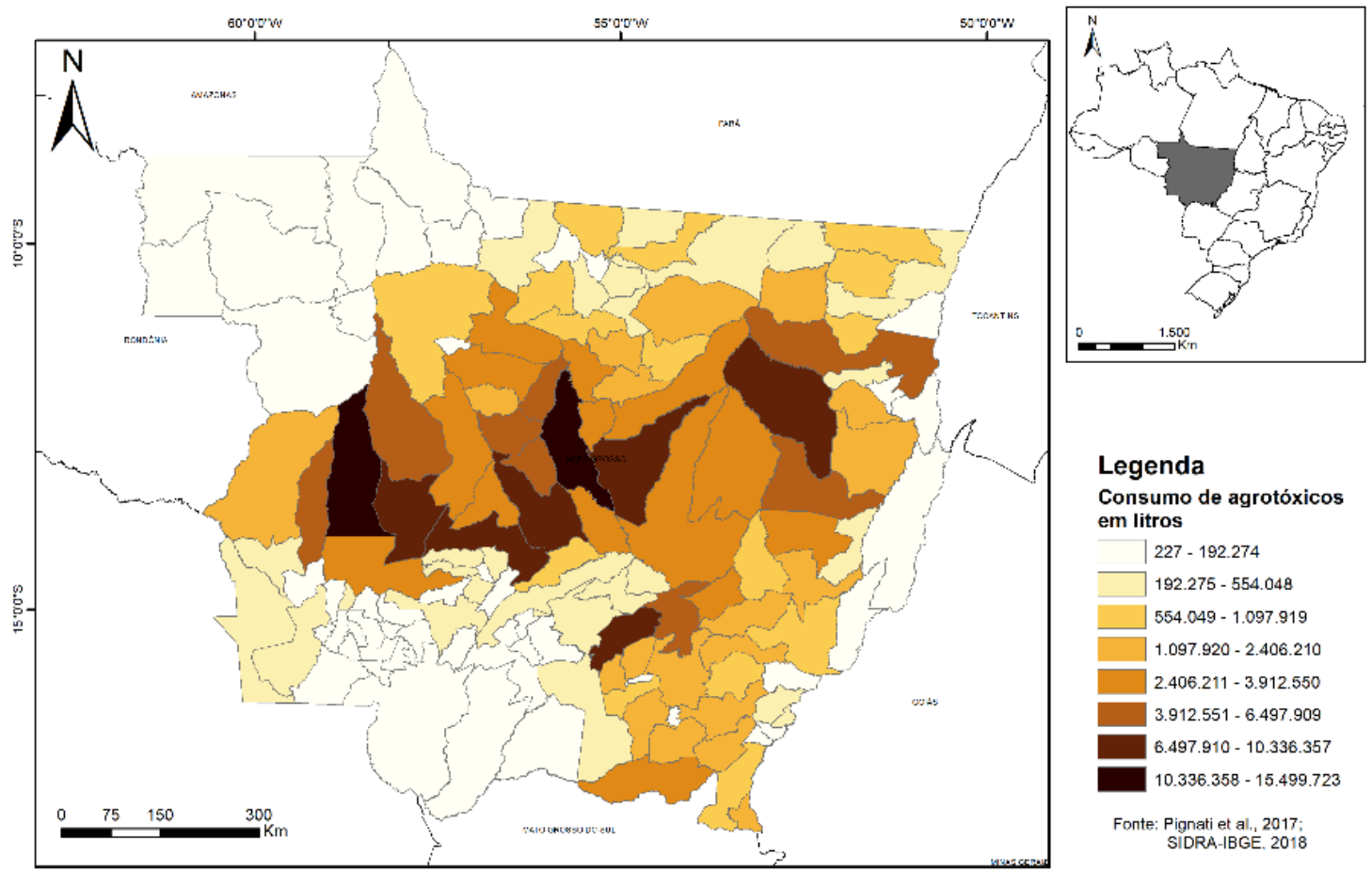

Legenda

Consumo de agrotóxicos em litros

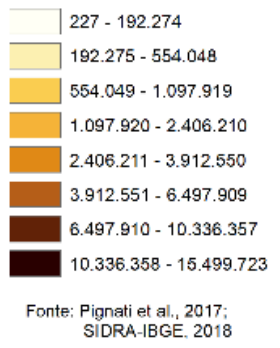

Figura 2. Mapa de Utilização de agrotóxicos por município do estado de Mato Grosso, 2017. Fonte: NEAST/ISC/UFMT, setembro de 2018. 
O estado de Mato Grosso é o maior produtor nacional de soja, milho, algodão, bovinos e lidera também o ranking quando se trata da utilização de agrotóxicos nas suas lavouras. Dos 141 municípios, 82 destinam parte de seus territórios à produção de monoculturas, tendo colhido área superior a 10 mil hectares de soja na safra 2016 (IBGE-CENSO AGROPECUÁRIO, 2017). Dentre estes municípios se destacam Campo Novo do Parecis, Campos de Júlio e Sapezal que fazem parte das bacias dos rios Juruena, Tapajós e Amazonas e localizam-se na porção oeste do estado de Mato Grosso. O processo de colonização dos territórios intensificouse na década de 1970 com o avanço das fronteiras agrícolas pelo estado de Mato Grosso. Atualmente, os municípios têm sua economia pautada pela produção de commodities agrícolas, estando classificados entre os 20 maiores PIB relativos ao agronegócio no Brasil (IBGE-SIDRA/PM, 2018).

O PIB per capita dos três municípios é em média $\mathrm{R} \$ 134$ mil, em valores atuais, cerca de quatro vezes o valor do PIB per capita estadual e nacional. A agricultura empresarial ocupa lugar de destaque na região que desponta no cenário nacional sob a administração de grandes (e poucos) grupos econômicos, além da concentração fundiária e produção hegemônica de commodities agrícolas. Os municípios, juntos, correspondem $10 \%$ da produção estadual em toneladas de soja, $12 \%$ do milho, $37 \%$ do algodão, $43 \%$ do girassol e $17 \%$ da cana-de-açúcar, enquanto contribui com $3 \%$ da produção estadual em toneladas de arroz e $12 \%$ do feijão (IBGE-SIDRA/PAM, 2018).

A maior parte dos estabelecimentos rurais nos três municípios, cerca de $74 \%$, tem acima de 2,5 mil hectares, com uma média de 6 mil hectares. Poucos estabelecimentos rurais têm menos de 100 hectares na região, correspondendo a uma área inferior a 5\% do total, sendo estas áreas majoritariamente destinadas à produção de commodities agrícolas e as áreas destinadas a agricultura camponesa pouco expressivas (OLIVEIRA et al, 2018). A região também utiliza elevados volumes de agrotóxicos, conforme aponta a figura 2, com média de 12 a 15 litros de produto formulado por hectare para todas as culturas produzidas no ano de 2017 (IBGE-SIDRA/PAM, 2018; PIGNATI et al, 2017).

Apesar de utilizar grande porção de seus territórios para a produção de grãos, cana e algodão, aproximadamente $96 \%$ dos territórios agriculturáveis dos três municípios, há uma dependência de alimentos produzidos em outras regiões, sobretudo frutas, hortaliças folhosas e não folhosas, arroz, feijão, leite e derivados, carnes e outros produtos, o que corresponde a um descompasso entre a produção local e regional e a produção de commodities. Tal fato é observado na definição dos territórios de produção, cuja hegemonia do modelo produtivo do agronegócio se insere até mesmo nas práticas agrícolas de pequenas propriedades nestes municípios, implicando na "homogeneização da produção agrícola", haja vista as dificuldades expressas em produzir alimentos "de outras formas", situações que evidenciam a ausência de discussões acerca da soberania e segurança alimentar e nutricional dos territórios em questão.

Para Altieri (2012), um dos principais problemas decorrentes da homogeneização dos sistemas agrícolas é o aumento da vulnerabilidade dos cultivos a pragas e doenças que podem ser devastadoras em grandes plantações, aumentando exponencialmente a utilização de agrotóxicos para combatê-las e reduzindo sua efetividade e seletividade. Também a ausência ou insuficiência de complementaridade entre as atividades agrícolas desempenhadas nas grandes fazendas e a dependência para a aquisição de sementes e insumos vulnerabilizam a sustentabilidade do modelo. 


\title{
Soberania e segurança alimentar e nutricional, o direito humano à alimentação adequada e à saúde: interface de conceitos
}

\begin{abstract}
A alimentação adequada é um direito humano fundamental, indispensável à realização dos direitos consagrados no Pacto Internacional dos Direitos Econômicos, Sociais e Culturais e na Constituição Federal Brasileira. Segundo a Lei Orgânica de Segurança Alimentar e Nutricional (LOSAN):

A Segurança Alimentar e Nutricional consiste na realização do direito de todos ao acesso regular e permanente a alimentos de qualidade, em quantidade suficiente, sem comprometer o acesso a outras necessidades essenciais, tendo como base práticas alimentares promotoras de saúde que respeitem a diversidade cultural e que sejam ambiental, cultural, econômica e socialmente sustentáveis. (LOSAN, Artigo $3^{\circ}$ )
\end{abstract}

Para seu efetivo alcance, preceitua a ampliação das condições de acesso aos alimentos por meio da produção, em especial da agricultura tradicional e familiar, a utilização sustentável dos recursos, a garantia de qualidade dos alimentos e o respeito à soberania.

A "ideia" de Soberania Alimentar vem sendo discutida desde a década de 1940, tendo como precursor no Brasil, Josué de Castro, médico pernambucano que discutia a questão da fome e da produção de alimentos como um determinante social produzido pelo capitalismo. A fome não era apenas descrita como um fenômeno biológico, mas como um fenômeno político, engendrado e produzido pela concentração de terras, ausência de reforma agrária e baixa tecnificação no campo, o que incorria em abandono das terras e migração para as cidades, acentuando a exclusão, a fome e as doenças (CASTRO, 2007).

Em Geografia da Fome, ele trata da questão alimentar brasileira tendo como cenário as décadas de 1940 e 1950, discutindo a precarização da agricultura brasileira, que à época utilizava técnicas "feudais" de produção, bem como a concentração de terras e a pobreza dos agricultores que, sem condições de produzir, migravam para as cidades.

\begin{abstract}
Mesmo industrializando-se, a nossa economia seguiu os ditames de uma economia de tipo colonial, politicamente desinteressada pela sorte da maioria, apenas ocupada em desenvolver mais o já desenvolvido e em enriquecer mais os já enriquecidos pelo sistema vigente. E é nesse aspecto desequilibrante que o nosso desenvolvimento econômico não corresponde a um autêntico desenvolvimento social, que representa a autêntica aspiração das massas brasileiras. (CASTRO, 2007: 275)
\end{abstract}

Apesar das contribuições de Josué de Castro, o conceito de Soberania Alimentar passou a ser discutido mais amplamente a partir de 1996 com a participação dos movimentos sociais de agricultores da Via Campesina na Cúpula Mundial de Alimentação, sendo compreendida como o direito dos povos a definir suas próprias políticas e estratégias sustentáveis de produção, distribuição e consumo de alimentos, respeitando suas próprias culturas (DESMARAIS, 2013: 41).

Dentre os compromissos da Declaração de Roma, a garantia do Direito $\mathrm{Hu}-$ mano a Alimentação Adequada, bem como a preocupação com a produção de alimentos de forma ambientalmente sustentável e justa, valorizando sistemas alimentares regionais e locais, priorizando a produção de alimentos para abastecimento local, com base nas necessidades alimentares e na cultura de cada país (DECLARAÇÃO DE ROMA, 1996), contrapunham a lógica mercadológica do modelo de agricultura imposta e fortalecida pela Revolução Verde. Para WITTMAN (2010: 92), um dos aspectos mais relevantes da perspectiva da Soberania 
Alimentar está em ampliar as discussões no campo da Segurança Alimentar e Nutricional, para além do acesso regular e permanente aos alimentos, numa perspectiva de promoção da reconexão entre alimentos, natureza e comunidades. Outros elementos estruturam a Soberania Alimentar: a luta contra a agricultura industrial corporativa, pelas devastações ambientais e sociais que provoca; a reafirmação do pequeno agricultor, no contexto atual da globalização; a perspectiva da constituição de uma nova ordem alimentar mundial, sustentável e socialmente justa (BERNSTEIN, 2015: 278).

A chamada "modernização da agricultura" gerou inúmeros impactos no ambiente e na saúde das pessoas, sendo as intoxicações por agrotóxicos um dos principais agravos entre os problemas de saúde (CARNEIRO et al, 2015). Além de acometer quem manipula diretamente os produtos formulados, seja na mistura ou na aplicação, estudos apontam para a elevada incidência de doenças associadas à exposição aos agrotóxicos em populações de regiões de intensa produção agrícola e que mais utilizam estes produtos em suas lavouras (MOREIRA et al, 2012; PIGNATI et al, 2017; RIGOTTO et al, 2013; MOSTAFALOU E ABDOHALLI, 2017).

Além da exposição aos agrotóxicos em alimentos in natura e processados, a reduzida diversidade de espécies que se consome na alimentação humana, intensifica a produção e o consumo de alimentos altamente industrializados, nutricionalmente pobres em vitaminas e minerais e ultraprocessados (MONTEIRO, 2013). Tal situação traz impactos à saúde, pois a diversidade de hábitos alimentares e os recursos naturais são importantes contributos para uma dieta rica em micronutrientes, que poderia ser melhor promovida por sistemas alimentares descentralizados, baseadas em circuitos regionais e locais de produção de alimentos, distribuição e consumo com base em uma agricultura familiar diversificada (MALUF et al, 2015: 2306) e ambientalmente sustentáveis, pautados em sistemas agroecológicos de produção (ALTIERI, 2012).

A ocupação desigual do território também afeta o trabalho e a saúde. Dados nacionais do Censo Agropecuário de 2017, recentemente publicados, apontam uma redução de $9,5 \%$ no número de estabelecimentos classificados como de agricultura familiar e redução de 2,2 milhões de postos de trabalho na agricultura familiar, em relação ao último Censo, de 2006 e, apesar de representar o maior contingente dos estabelecimentos agrícolas do país (77\%), ainda ocupam uma área menor equivalente a 80,89 milhões de hectares, ou 23\% da área agrícola total do país.

Para BREILH a ligação entre o sistema agrícola e a saúde não está reduzida à relação entre abastecimento e consumo de alimentos, mas amplia-se para a determinação de problemas de saúde como excesso de peso, diabetes, várias formas de câncer, intoxicação crônica e aguda, malformações congênitas e deficiências (BREILH, 2016). A produção de alimentos está associada ao processo de industrialização, urbanização das cidades no período pós-guerra, ao êxodo rural e às intensas transformações nos modos de consumo das pessoas. Neste sentido está também associada às mudanças nos perfis de ocupação dos territórios, alterando as próprias relações sociais. Consequentemente é um fenômeno associado à questão da saúde. 


\section{Imposição dos agrotóxicos nos territórios de produção agrícola e além}

Olhar para a ocupação dos territórios de produção agrícola sob o viés do Realismo Dialético implica em analisar as dimensões real e atual (BREILH, 2006; OLIVEIRA et al, 2017), da imposição do uso de agrotóxicos e suas implicações na disponibilidade de alimentos, poluição ambiental e contaminação da água e dos alimentos que abastecem estas regiões.

Milton Santos discute o conceito de territórios para além de um espaço geográfico delimitado, ampliando-se para as relações sociais e de poder, os modos de vida, as formas de reprodução social determinando seu processo de ocupação e legitimação (SANTOS, 2001). Atualmente, os territórios tendem a sofrer uma "compartimentação generalizada", no qual a interface entre os movimentos gerais da sociedade global e os movimentos particulares de cada ação local e regional se confrontam (SANTOS, 2001: 37) movimentos que, segundo o autor, retiram a capacidade de decisão das pessoas sobre seus destinos, tal qual se observa na ocupação de territórios pela agricultura moderna, cientificada e mundializada, em países como o Brasil (SANTOS, 2001).

Os territórios do interior do Brasil são hoje ocupados hegemonicamente por uma agricultura mecanizada e tecnológica, sob gestão empresarial fortemente associada às perspectivas liberais de acumulação de capital, que se organiza e se insere em todos os campos da vida social, o econômico, o político, o sanitário, o ambiental. Sob um discurso neomalthusiano de ampliação das capacidades produtivas dos territórios para atender à crescente demanda mundial por alimentos, o agronegócio se justifica, se autorregula e legitima um discurso de homogeneização dos modos de vida, ampliando a acumulação de capital por pilhagem dos recursos naturais, explorando os territórios em toda sua capacidade produtiva e expondo as populações aos riscos deste processo produtivo degradante.

As diferentes formas de se produzir e consumir alimentos foram se transformando à medida que o capitalismo, a industrialização e, mais recentemente as novas tecnologias foram incorporando novas formas de organização social, processo desenvolvido e experimentado de diferentes formas em diferentes lugares do mundo pelos grupos sociais, territórios e países. Mazoyer e Roudart (2010) chamam a atenção para as desigualdades entre as diferentes formas de agricultura praticadas no mundo e colocam duas perspectivas principais mediante as quais os problemas alimentares da humanidade foram evidenciados, acentuando-se estas desigualdades: a Revolução Agrícola Contemporânea, caracterizada pela elevada motorização, mecanização, seleção de variedades de plantas e de raças de animais, utilização de fertilizantes e produtos para tratamento de plantas e animais domésticos e a Revolução Verde, que avançou na especialização e tecnificação da agricultura e na modernização dos mercados de circulação global de mercadorias e insumos agrícolas.

Para os autores, estas formas de agricultura não foram acessíveis a todos os agricultores do mundo, os quais permaneceram na agricultura camponesa não mecanizada, sofreram os impactos da baixa dos preços reais de produção, desigualdades no acesso às terras e aos insumos, além das poluições ambientais, obrigando muitos ao êxodo rural e consequente migração para as periferias das cidades ou para áreas pouco produtivas, perfazendo um cenário de empobrecimento extremo e fome (MAZOYER E ROUDART, 2010). As populações rurais mais pobres e grupos tradicionais, como indígenas e quilombolas, permanecem submetidos e expostos às injustiças socioambientais ainda hoje (ONU, 2017). 
Diante da atual divisão internacional do trabalho e do processo de globalização em curso, o Brasil - e a América Latina como um todo - têm reforçado um modelo econômico fortemente voltado ao seu papel enquanto exportador de mercadorias baseadas nos recursos naturais, como é o caso dos produtos do agronegócio, da mineração e da siderurgia, setores de especial relevância na exportação brasileira (PORTO, 2007: 509).

O modelo de dominação do capital pela comercialização de alimentos no mercado mundial influi muito negativamente na estrutura produtiva familiar camponesa, sendo que a isso se liga a práxis difundida pelas transnacionais agroquímico-alimentar-financeiras, de que a produção agropecuária tem que servir aos mercados (THOMAZ JÚNIOR, 2013: 370).

Nesta direção, o cenário atual aponta para a formação de oligopólios transnacionais que dominam a produção e o consumo de alimentos no mundo, com a fusão de empresas em complexos agroindustriais (PELAEZ, 2013), além das grandes redes de supermercados e marcas de alimentos industrializados. Para Maluf et al, 2015, tal processo de produção baseado em larga escala por monoculturas altamente mecanizadas estão inter-relacionadas com tendências atuais para a monotonia alimentar e o empobrecimento das dietas alimentares, refletindo a ausência de políticas de Soberania Alimentar (MALUF et al, 2015: 2305).

Por outro lado a falta de investimentos nas formas sustentáveis de agricultura e no fortalecimento da agricultura camponesa e familiar, evidenciam a iniquidade no acesso a terra e ao alimento, com cenários futuros apontando para o aumento das desigualdades, da fome e das doenças crônicas e subcrônicas relacionadas à alimentação em todo o mundo. Para Mazoyer e Rodart (2010), cenário duplamente malthusiano do qual o aumento de produção agrícola pela tecnificação dos métodos não resolverá a questão se não forem discutidas a produção local sustentável e a circulação das mercadorias em nível global, pautada em princípios éticos, não pelas vicissitudes dos mercados, pois "os produtos agrícolas e alimentares não são mercadorias como as outras: seu preço é o da vida e, abaixo de um certo patamar, o da morte" (MAZOYER e ROUDART, 2010: 34).

A "imposição" aos agrotóxicos subscreve a ocupação dos territórios pelo modelo hegemônico de produção e se desdobra em diversas outras evidências, como a contaminação das águas e dos alimentos nos municípios brasileiros. A contaminação das águas de abastecimento tem sido recentemente discutida, a partir da publicação dos resultados do SISÁGUA, programa do Ministério da Saúde, responsável pelo monitoramento das águas de abastecimento nos municípios, cuja periodicidade de análise para resíduos de agrotóxicos é semestral, conforme preconiza a Portaria de Potabilidade da água 2914/2011 (MS, 2011). Os resultados apontam que em 1.396 municípios brasileiros, abrangendo uma população total de mais de 85 milhões de pessoas, há traços de todos os 27 agrotóxicos na água para consumo humano pelo menos uma vez entre 2014 e 2017, estando a maioria localizado no corredor agroindustrial do Brasil, estendendo-se do Sul/Sudeste ao Centro-Oeste e até o Nordeste (GABERELL E HOINKES, 2019).

Com relação ao monitoramento de resíduos de agrotóxicos em alimentos, o programa da ANVISA denominado PARA (Programa de Análises de Resíduos de Agrotóxicos em Alimento) vem realizando análises de presença de resíduos de agrotóxicos em vegetais desde sua implantação em 2001. Em seu último relatório, evidenciou a presença de resíduos de agrotóxicos em 70\% das 12 mil amostras de alimentos testadas entre 2013 e 2015, sendo que 20\% das amostras apresentaram resíduos de agrotóxicos que excederam os níveis permitidos ou continham agrotóxicos não autorizados para cultura (PARA/ANVISA, 2015). Ainda que existam 
programas de monitoramento vinculados ao Ministério da Saúde, não há uma atuação mais intensa dos órgãos governamentais no sentido de rastrear a produção e promover a correção das cadeias produtivas. Análises caras, não abrangentes da totalidade de ingredientes ativos autorizados no Brasil, processos de coleta feitos por amostragem e o não cumprimento da periodicidade da análise da água de consumo pelos municípios evidenciam que os resultados de contaminação podem ser mais graves que os atualmente apresentados e divulgados pelos programas de monitoramento.

Nesta perspectiva a exposição aos agrotóxicos abrange toda a população, em graus variáveis, desde uma exposição mais intensa em territórios de produção agrícola até a exposição aos resíduos presentes em alimentos e na água de abastecimento, resquícios de um modelo que desconsidera a saúde e a vida. Essa exposição tem caráter impositivo, pois desconsidera o direito humano à alimentação adequada ao não garantir o acesso à informação sobre os modelos produtivos, uso de agrotóxicos, presença de resíduos e riscos à saúde, além da insuficiência de políticas públicas de incentivo à produção de alimentos por outros modelos produtivos mais sustentáveis e não químico - dependentes.

\section{Considerações finais}

A relação entre produção de alimentos, soberania alimentar e saúde se dá na interface de diversos fatores: a contaminação da água de consumo, do ar, dos rios, dos alimentos repercute de forma aguda e crônica no processo de adoecimento das populações e representam importantes mecanismos na determinação social do processo saúde-doença, com base na imposição às consequências do modelo de produção químico-dependente.

A ausência de informações ao consumidor de alimentos e água acerca dos modelos de produção e seus processos apontam a manipulação das informações de contaminação e distanciamento entre os consumidores e produtores, entre o ser humano e o alimento. Exemplos disso são:

1. Expansão desenfreada e desregulada das áreas de produção de monocultivos em detrimento de áreas destinadas à produção familiar, em circuitos locais e regionais, evidenciando a ausência de áreas livres de agrotóxicos para a produção de alimentos orgânicos e agroecológicos nos territórios estudados e no estado de Mato Grosso, dificultando este tipo de produção no estado;

2. Ausência de informações sobre os transgênicos: quais são, para que servem, quais seus possíveis impactos à saúde dos consumidores, dos sistemas produtivos e do ambiente; apesar de haver legislação que obriga a indústria a informar o uso de alimentos transgênicos na composição de alimentos industrializados, grande parte da população desconhece seus conceitos, usos e riscos, ainda que parte expressiva dos territórios de Mato Grosso seja destinada ao plantio de sementes transgênicas.

3. Informações sobre tipos de lavouras (convencionais, orgânicas, transgênicas, agroecológias, sintrópicas). A ausência de informações sobre as formas de se produzir os alimentos transfere a mensagem de que há 
apenas uma única forma possível de produção de alimentos, induzindo uma narrativa de defesa do agronegócio em detrimento dos seus riscos sanitários e ambientais.

4. Ausência de transparência na divulgação de informações sobre comercialização e utilização dos agrotóxicos, condições climáticas de aplicação, misturas realizadas nas caldas, com potencial tóxico de interação e sinergia.

5. Ausência de informações acerca de resíduos de agrotóxicos em alimentos. As análises do PARA são escassas, irregulares, representam uma pequena amostra dos alimentos de origem vegetal produzidos e consumidos no país e sua divulgação sofre interferências políticas, não permitindo uma atuação sanitária corretiva das cadeias produtivas de alimentos em tempo hábil. As mudanças nas metodologias de divulgação dos resultados dos relatórios do PARA/ANVISA de avaliação da ingestão crônica para avaliação de risco de ingestão aguda, o fato de não analisar produtos de origem animal e desconsiderar o monitoramento dos agrotóxicos mais utilizados no país, tais como glifosato, paraquat e 2,4-D, evidenciam que há lacunas de informação e que os cenários de contaminação alimentar por agrotóxicos podem ser ainda mais complexos;

6. Os Limites Máximos de Resíduo (LMR) de agrotóxicos em alimentos, assim como os Valores Máximos Permitidos (VMP) na água são maiores em comparação a outras legislações (BOMBARDI, 2017). Tal condescendência também se reflete nas mudanças de classificação toxicológica dos agrotóxicos autorizados no Brasil, além da liberação de 325 agrotóxicos até setembro de 2019, sendo 310 são produtos genéricos e 15 à base de ingredientes ativos novos (MAPA, 2019), alguns dos quais extremamente tóxicos e proibidos na União Europeia, como é o caso do inseticida Dinotefuram, que será utilizado nas culturas de arroz, aveia, batata, café, cana-de-açúcar, centeio, cevada, citros, feijão, milheto, milho, pastagem, soja, tomate, trigo e triticale (ANVISA, 2019);

7. Ausência de fiscalização do uso de agrotóxicos e do cumprimento das Boas Práticas Agrícolas na produção de hortaliças e produtos hortícolas, tanto em escala comercial como da produção da agricultura familiar, bem como insuficiência no financiamento e nas ações de assistência técnica rural para a promoção de agricultura não químico-dependente.

Diante das evidências de que o modelo produtivo do agronegócio tem imposto um padrão alimentar homogeneizado para garantir o consumo, ampliado o uso de agrotóxicos e fertilizantes químicos, degradado o ambiente, exaurido os recursos naturais, estabelecendo desigualdades nos territórios e promovendo doenças, esta é uma discussão cada vez mais necessária e proeminente, tanto no campo da produção de alimentos quanto no campo da saúde.

Assim, as estratégias de redução gradual do uso de agrotóxicos por meio de regulação, fiscalização e controle, correções das cadeias produtivas e informações 
ao consumidor quanto à qualidade sanitária dos alimentos contribuem para a definição de territórios e modelos de produção de alimentos mais saudáveis, sustentáveis e justos. A garantia das condições de acesso e permanência nas áreas rurais, bem como às condições técnicas e materiais de manejo da terra e a definição de áreas livres de agrotóxicos e transgênicos também são elementos importantes, cuja discussão deve estar presente na agenda das políticas públicas que considerem a saúde e não apenas o desenvolvimento econômico como ponto de partida.

São necessários investimentos de pesquisas que promovam a produção e consumo saudável e sustentável de alimentos, ampliando as narrativas de defesa de um modelo de produção local para abastecimento de circuitos curtos e médios de consumo, possibilitando a interação entre produção e consumo, promovendo o re-conhecimento das técnicas de produção agroecológicas e a reconexão do ser humano ao alimento e à natureza.

Recebido em 18 de setembro de 2019. Aprovado em 29 de outubro de 2019.

\section{Referências Bibliográficas}

ALTIERI, M. “Agroecologia: princípios e estratégias para o desenho de sistemas agrícolas sustentáveis”. In: ALTIERI, M. Agroecologia: bases científicas para uma agricultura sustentável. São Paulo: Expressão Popular; Rio de Janeiro: AS-PTA, 2012. pp. 103-115.

AGÊNCIA NACIONAL DE VIGILÂNCIA SANITÁRIA (BRASIL). Programa de Análise de Resíduos de Agrotóxicos em Alimentos. Relatório de Atividades 2013-2015. Brasília/DF, 2015. Disponível em:

http://portal.anvisa.gov.br/programa-de-analise-de-registro-de-agrotoxicospara Acesso em 05/11/2018.

AGÊNCIA NACIONAL DE VIGILÂNCIA SANITÁRIA (BRASIL). Consulta Pública sobre Inclusão de monografia do Dinotefuram. Consulta Pública ${ }^{\circ}$ 644, de 21 de maio de 2019. Brasília/DF, 2019. Disponível em: http://portal.anvisa.gov.br/documents/10181/5505175/CONSULTA+P\%C3\%9 ABLICA+N+644+GGTOX.pdf/109ee8f6-a45f-482d-83f4-dogead58e7c9. Acesso em 10/09/2019.

ARAÚJO, I. M. M.; OLIVEIRA, A. G. R. C. Agronegócio e Agrotóxicos: Impactos à Saúde dos Trabalhadores Agrícolas do Nordeste Brasileiro. Trab. Educação e Saúde, 15(1): 117-129, 2017.

BERNSTEIN, H. Soberania Alimentar: uma perspectiva cética. Sociologias; 39: 276-336, 2015.

BOMBARDI, L. M. Atlas Geografia do Uso de Agrotóxicos no Brasil e Conexões com a União Européia. Laboratório de Geografia Agrária. FFLCH - USP, São Paulo, 2017. 
BRASIL. LEI No 11.346, DE 15 DE SETEMBRO DE 2006. Lei Orgânica da Segurança Alimentar e Nutricional - LOSAN. Cria o Sistema Nacional de Segurança Alimentar e Nutricional. SISAN com vistas em assegurar o direito humano à alimentação adequada e dá outras providências. Diário Oficial da União 18/09/2006.

BREILH, J. Epidemiologia Crítica: Ciência Emancipadora e Interculturalidade. Rio de Janeiro: Editora FIOCRUZ, 2006. 317p.

BREILH, J. Hacia una redefinición de la soberanía agraria: ¿es posible la soberanía alimentaria sin cambio civilizatorio y bioseguridad? In: BEZERRA, I; PEREZ-CASSARINO, J. (orgs.). Soberania Alimentar (SOBAL) e Segurança Alimentar e Nutricional (SAN) na América Latina e Caribe. Curitiba: Ed. UFPR, 2016. pp. 55-68.

CARNEIRO, F.; GIRALDO, L.; PIGNATI, W.A. et al. Dossiê ABRASCO: um alerta sobre os impactos dos agrotóxicos na saúde. Rio de Janeiro: EPSJV; São Paulo: Expressão Popular, 2015.

CASTRO, J. Geografia da Fome. O dilema brasileiro: pão ou aço. $7^{\text {a }}$ Ed. Rio de Janeiro: Civilização Brasileira, 2007. 318 p.

CONSELHO NACIONAL DE SEGURANÇA ALIMENTAR E NUTRICIONAL. CONSEA. Mesa de controvérsias sobre impactos dos agrotóxicos na soberania e segurança alimentar e nutricional e no direito humano à alimentação adequada: relatório final. Brasília: Presidência da República, 2014.

DESMARAIS, A. A. A Via Campesina: A Globalização e o Poder do Campesinato. São Paulo: Cultura Acadêmica; Expressão Popular, 2013.

GABERELL, L; HOINKES, C. Lucros altamente perigosos. Como a Syngenta ganha bilhões vendendo agrotóxicos nocivos: Um Relatório da Public Eye, Lausanne: Public Eye, 2019. Disponível em:

https://www.publiceye.ch/fileadmin/doc/Pestizide/2019_PublicEye_Lucros_a ltamente_perigosos_Report.pdf. Acesso em 10/09/2019.

HOBSBAWN, E. A. Era dos Extremos: O breve século XX. 1914-1991. São Paulo: Companhia das Letras, 2014. 632 p.

HOLANDA, S. B. Raízes do Brasil. Edição Crítica 8 o anos. 1936-2016. São Paulo: Companhia das Letras, 2016.

INSTITUTO BRASILEIRO DE GEOGRAFIA E ESTATÍSTICA - IBGE. (BRASIL) Sistema IBGE de Recuperação Automática SIDRA [internet]. Produção Agrícola Municipal. 2017. [Acesso em 2018 dez 10]. Disponível em: https://sidra.ibge.gov.br/pesquisa/pam/tabelas.

INSTITUTO BRASILEIRO DE GEOGRAFIA E ESTATÍSTICA - IBGE. (BRASIL) Censo agropecuário 2017 - Resultados Preliminares [internet]. [Acesso em 2018 ago 08]. Disponível em:

https://censos.ibge.gov.br/agro/2017/templates/censo agro/resultadosagro/in dex.html.

INSTITUTO BRASILEIRO DE GEOGRAFIA E ESTATÍSTICA - IBGE. (BRASIL) Censo agropecuário 2017 [internet]. [Acesso em 2019 out 20]. Disponível em: https://censos.ibge.gov.br/agro/2017/

INSTITUTO BRASILEIRO DE GEOGRAFIA E ESTATÍSTICA - IBGE. (BRASIL) 
Distrito federal; 2018. Acesso em 20/12/2018. Disponível em: https://sidra.ibge.gov.br/pesquisa/pib-munic/tabelas

MALUF, R. S. ; BURLANDY, L. ; SANTARELLI, M. et al. Nutrition-sensitive agriculture and the promotion of food and nutrition sovereignty and security in Brazil. Ciência e Saúde Coletiva, 20 (8): 2303 -2312, 2015.

MARTINS, T. M. Ciclos e Previsão Cíclica dos preços de commodities: um modelo de indicador antecedente para a commodity açúcar. Tese de Doutorado. USP, 2009.

MARX, K. O Capital. Volume I. 2 Edição. São Paulo: Boitempo Editorial, 2011. 894 p.

MAZOYER, M.; ROUDART, M. História das agriculturas no mundo: do neolítico à crise contemporânea. São Paulo: Editora UNESP; Brasília, DF: NEAD, 2010. 568p.

MEDINA, G.; RIBEIRO, G. G.; BRASIL, E. M. Participação do capital brasileiro na cadeia produtiva da soja: lições para o futuro do Agronegócio Nacional. Revista de Economia e Agronegócio, 13 (1,2,3): 3-38, 2015.

MELGAREJO, L. "Lavouras Transgênicas: Uma discussão sobre a tecnologia, seus mitos e alguns dos impactos documentados”. In: MESQUITA, M.O.; RIQUINHO, D. L.; GERHARDT, T. E. et al (orgs.). Saúde coletiva, desenvolvimento e (in)sustentabilidades no rural. Porto Alegre: Editora da UFRGS, 2018. pp. 15-50.

MENDONÇA, M. L. O Papel da Agricultura nas Relações Internacionais e a Construção do Conceito de Agronegócio. Contexto Internacional, 37 (2): 375402, 2015 .

MINISTÉRIO DA AGRICULTURA, PECUÁRIA E ABASTECIMENTO - MAPA. Ato $\mathrm{n}^{0}$ 62. Liberação de registro de agrotóxicos. Publicado no DOU Edição 180; Seção 1, pag. 4. em 17/09/2019.

MINISTÉRIO DA SAÚDE (BRASIL). Portaria G. M. 2914 de 12 de dezembro de 2011. Dispõe sobre os procedimentos de controle e de vigilância da qualidade da água para consumo humano e seu padrão de potabilidade. Diário Oficial da União. 12/12/2011.

MIRANDA, A. C.; MOREIRA, J. C.; CARVALHO, R.; PERES, F. Neoliberalismo, uso de agrotóxicos e a crise da Soberania Alimentar no Brasil. Ciência e Saúde Coletiva, 12 (1): 7-14, 2007.

MONTEIRO, C. A. Nutrition and health. The issue is not food, nor nutrients, so much as processing. Public Health Nutr., 12 (5): 729-31, 2009.

MONTEIRO, C. A.; MOUBARAC, J. C.; CANNON, G.; NG, S. W.; POPKIN, B. Ultra-processed products are becoming dominant in the global food system. Obesity Reviews, 14 (Suppl 2): 21-28, 2013.

MOREIRA, J.; PERES, F.; SIMÕES. A.C. et al. Contaminação de águas superficiais e de chuva por agrotóxicos em uma região de Mato Grosso. Ciência e Saúde Coletiva, 17 (6): 1557-1568, 2012.

MOSTAFALOU, S.; ABDOLLAHI, M. Pesticides: an update of human exposure and toxicity. Arch Toxicol., 91: 549-599, 2017. 
OLIVEIRA L. K.; PIGNATI, W. A.; PIGNATTI, M. G.; BESERRA. L.; LEÃO, L. H. C. Processo sócio-sanitário-ambiental da poluição por agrotóxicos na bacia dos rios Juruena, Tapajós e Amazonas em Mato Grosso, Brasil. Saúde e Sociedade, 27(2): 573-587, 2018.

OLIVEIRA, A. U. A Mundialização da Agricultura Brasileira. São Paulo: Iandé Editorial, 2016. 545 p.

ORGANIZAÇÃO MUNDIAL DE SAÚDE (OMS). ORGANIZAÇÃO DAS NAÇÕES UNIDAS PARA A ALIMENTAÇÃO E AGRICULTURA (FAO). Declaração de Roma sobre a Segurança Alimentar Mundial e Plano de Ação da Cúpula Mundial de Alimentação. Roma, 1996. Disponível em:

http://www.fao.org/docrep/o03/W3613P/W3613Poo.htm. Acesso em 25/11/2016.

ORGANIZAÇÃO DAS NAÇÕES UNIDAS (ONU). Relatório do Relator Especial sobre o Direito à Alimentação. Assembléia Geral das Nações Unidas, 2017.

PELAEZ, V.; SILVA, L. R.; ARAÚJO, E. B. Regulation of pesticides: A comparative analysis. Sci public policy, 40 (5): 644-656, 2013.

PIGNATI, W. A.; MACHADO, J. M. H. "O agronegócio e seus impactos na saúde dos trabalhadores e da população de MT”. In: GOMEZ, C. A. M. (org.). Saúde do trabalhador na sociedade brasileira contemporânea. RJ: Fiocruz; 2011; p 245272.

PIGNATI, W.; LIMA, F. A. N. S.; LARA, S. S.; MONTANARI CORRÊA, M. L.; BARBOSA, J. R.; PIGNATTI, M. G. Distribuição espacial do uso de agrotóxicos no Brasil: uma ferramenta para a vigilância em saúde. Ciência e Saúde Coletiva, 22 (10): 3281-3293, 2017.

PORTO, M. F.; MARTINEZ-ALIER, J. Ecologia política, economia ecológica e saúde coletiva: interfaces para a sustentabilidade do desenvolvimento e para a promoção da saúde. Cadernos de Saúde Pública, 23 (Suppl 4): S503-12, 2007.

PORTO, M. F.; SOARES, W. L. Modelo de Desenvolvimento, Agrotóxicos e Saúde: um panorama da realidade agrícola brasileira e propostas para uma agenda de pesquisa inovadora. Rev. bras. Saúde ocup., 37 (125): 17-50, 2012.

PRADO, J. R.C. A Questão Agrária. 4a Edição. São Paulo: Brasiliense, 1979.

RIGOTTO, R. M; VASCONCELOS, D. P.; ROCHA, M. M. Uso de agrotóxicos no Brasil e problemas para a saúde pública. Cad. Saúde Pública, 30 (7): 1-3, 2014.

SANDRONI, P. Novíssimo Dicionário de Economia. São Paulo: Círculo do Livro/Editora Best Seller, 1999.

SANTOS, M. Por uma outra globalização: do pensamento único à consciência universal. $6^{\mathrm{a}}$ ed. Rio de Janeiro: Record, 2001.

SANTOS, T. G.; SILVEIRA, J. A. C.; LONGO-SILVA, G. et al. Tendência e fatores associados à insegurança alimentar no Brasil: Pesquisa Nacional por Amostra de Domicílios 2004, 2009 e 2013. Cad. Saúde Pública, 34 (4): eooo66917, 2018.

SEGALL-CORRÊA, A. M.; PEREZ-ESCAMILLA, R.; MARIN-LEON, L. et al. Evaluation of household food insecurity in Brazil: validity assessment in diverse sociocultural settings. Concurso RedSan, 2007, 2009. Acesso em 20/11/2018. 
Disponível em:

http://www.bvsde.paho.org/texcom/nutricion/memredsan 3.pdf

THOMAZ JUNIOR, A. "O Tecido social do Trabalho, a produção de alimentos versus agronegócio e luta de classes num ambiente de embates e debates". In: LOURENÇO, E. A. S.; NAVARRO, V. L. (orgs). O Avesso do Trabalho III: Saúde do Trabalhador e questões contemporâneas. São Paulo: Outras Expressões, 2013. pp. 367-393.

WITTMAN, H. "Reconnecting agriculture \& the environment: food sovereignty \& the agrarian basis of ecological citizenship". In: WITTMAN, H.; DESMARAIS. A. A.; WIEBE, N. (eds.). Food Sovereignty. Reconnecting Food, Nature and Community. Vancouver/Canada: Fernwood Publishing, 2010. pp. 91-105. 